sis identifies those pesticides that are potential candidates for removal from use as a result of these regulatory actions.

In the second, Frank Zalom and Joyce Strand provide a preliminary glimpse of a large database that identifies various alternatives and options currently available for pest control in the absence of those pesticides discussed by Stimmann and Ferguson. The database was developed from the responses to a questionnaire distributed to Cooperative Extension advisors and specialists with pest management responsibilities as well as to Agricultural Experiment Station and USDA-Agricultural Research Service scientists. Data for each crop and pesticide combination include the target pest, alternative pesticides, alternative nonchemical controls, constraints to the rapid adoption of some of these alternatives, and the research agenda needed to develop effective alternatives.

While the questionnaire's excellent response yielded an extensive database, a number of data gaps remain. The pest management departments and specialists are now reviewing the database, seeking to expand and further refine the list of alternatives and to explore the nature of constraints that currently restrict the efficacy of otherwise viable alternatives. The database is also in the process of being analyzed by economists to determine on-farm cost comparisons where they are possible. That analysis will be published as a separate report upon its completion in August.

In the final report of the current series, Mary Louise Flint provides a general description of the various pest management options and a summary of critical areas needing additional, accelerated research for each alternative. A research database developed from the questionnaire described above and from the efforts of subjectarea workgroups categorizes the pest management options as biological, cultural, or chemical in nature. The researchers are now reviewing the database to further define research needs, catalog ongoing research activities, and provide the time-frame for introducing viable alternatives to specific pesticide uses.

This database will be valuable in determining the research agenda and setting priorities for future activities, both for redirection of existing research resources and assigning new funds that may be made available for the development of alternatives to the use of pesticides. For example, the California Environmental Protection Act of 1990 , if approved by the voters, would provide $\$ 20 \mathrm{mil}-$ lion in competitive grants for applied research and extension on alternatives to pesticides in agriculture, including interdisciplinary projects on alternative farming systems, methods, processes, and technologies.

Similarly, another proposed initiative measure, the Consumer Pesticide Enforcement Act for Food, Water, and Worker Safety, authorizes an appropriation of $\$ 5$ million each year for research awards to conduct pest management research projects, with an emphasis on alternatives to pesticides, use of safer pesticides, and farm management practices that result in the reduction of pesticide use or the minimization of pesticide residue. The database developed in our study would help focus these resources on the critical research areas. This initiative has not been included in our series of reports because it does not propose the cancellation of any chemical registrations, and therefore falls outside the scope of this review.

Tom Lanini, Dave Bayer, Becky Westerdahl, Jim Stapleton, Bees Butler, and Karen Klonsky helped design the survey. Lanini, Westerdahl, Stapleton, and Bayer led the discipline workgroups and helped assemble the data. The writers of the IPM Education and Publications Group helped organize and interpret survey responses. Buz Dreyer created the database program, and Christine Spainhower entered the data.

The database on pest control alternatives is the result of the unselfish contributions of the University of California Cooperative Extension and Experiment Station staff, who gave their valuable time to share their knowled ge in the original survey and in workgroup meetings.

\section{Selected references}

Choices, "Regulating chemicals," S. O. Archibald. First Quarter 1990.

Chemicals in the human food chain, C. K. Winter, J. N. Seiber, and C. F. Nuckton. Van Nostrand Reinhold, 1990.

University of California Agricultural Issues Center, "Chemicals in the human food chain: sources, options, and public policy," H. O. Carter and C. F. Nuckton, eds., Symposium, June 2-3, 1988.

Division of Water Quality, State Water Resources Board, "The status of agricultural drainage problems in California, 1989," B. Hanson and K. K. Tanji, August 1989.

Confluence of Change: The Great Central Valley, "Water: stretching the limits," K. K. Tanji, Symposium, May 1990.

Pesticide Analytical Methodology, "Analysis of pesticidal residues in the air near agricultural treatment sites," J. M. Seiber, G. A. Ferreria, B. Hermann, and J. E. Woodrow, American Chemical Society Symposium Series, 136, 1980.

James M. Lyons is Assistant Director of Programs for the Division of Agriculture and Natural Resources, based at Kaiser Center in Oakland and at UC Davis; and Frank G. Zalom is Director, Statewide IPM Project,IPM Implementation Group, and Extension Entomologist, based at UCC Davis.

\title{
Potential pesticide use cancellations in California
}

\author{
Michael W. Stimmann Mary P. Ferguson
}

Increasingly, pesticide registrations are being rescinded by state and federal regulatory actions and by private sector decisions to withdraw pesticide products. Public concern, regulatory complexity, and scientific understanding of the hazards of pesticides are likely to increase in the near future. California faces the potential loss of a large part of the currently employed chemical pest control technology. An understanding of these pesticide losses will help California's agricultural community identify and adopt effective and acceptable alternative pest management techniques and help the University of California make informed decisions on directing its research and extension resources.

We have reviewed the potential impact of two existing laws and one proposed law affecting agricultural pesticide use in California, in order to identify the pesticides that might be targeted for cancellation. These laws are the Safe Drinking Water and Toxic Enforcement Act of 1986 (Proposition 65), the Federal Insecticide, Fungicide, and Rodenticide Act as amended in 1988 (FIFRA 1988), and an initiative measure on the November 1990 ballot, the Environmental Protection Act of 1990 (EPA 1990). The potential impacts of these laws range from a requirement that a warning statement accompany pesticide-treated produce to the partial or complete cancellation of the pesticides' agricultural use.

The three measures may be thought of as a series of progressively more restrictive filters. Pesticide use is currently unaffected under Proposition 65, and many uses of most products will continue beyond the reregistration process required by FIFRA 1988. 
TABLE 1. Potential pesticide registration actions under Proposition 65

IMPACT: Does not cancel pesticide use; focuses on providing information to consumers at the marketplace. Some pesticides are not used on food crops in the U.S.

CRITERIA FOR INCLUSION ON THIS LIST: Identified by the California Scientific Advisory Panel or by a recognized authoritative body as being known to cause cancer or reproductive toxicity.

LIST: 20 registered active ingredients

\begin{tabular}{lc}
\hline Fungicides: & (continued) \\
cadmium \& its compounds & amitrole \\
captan & oxadiazon \\
chlorothalonil & Insecticides: \\
folpet & dichlorvos \\
formaldehyde & lindane \\
mancozeb & paradichlorobenzene \\
maneb & Nematicides: \\
metiram & $1,3-$ dichloropropene \\
zineb & Others: \\
Herbicides: & ethylene oxide \\
acifluorfen & propylene oxide \\
alachlor & warfarin \\
\hline
\end{tabular}

TABLE 2. Potential pesticide registration actions under FIFRA 1988

IMPACT: More than 4,000 pesticide uses on food crops are subject to reregistration under this federal law. Approximately 1,000 high-priority minor uses wili not be supported by the registrants and could be lost. ${ }^{*}$ One or more uses of each chemical on the list could be canceled.

CRITERIA FOR INCLUSION ON THIS LIST: Registrant not willing to provide data required by EPA for continued use on one or more crops.

LIST: 80 registered active ingredients

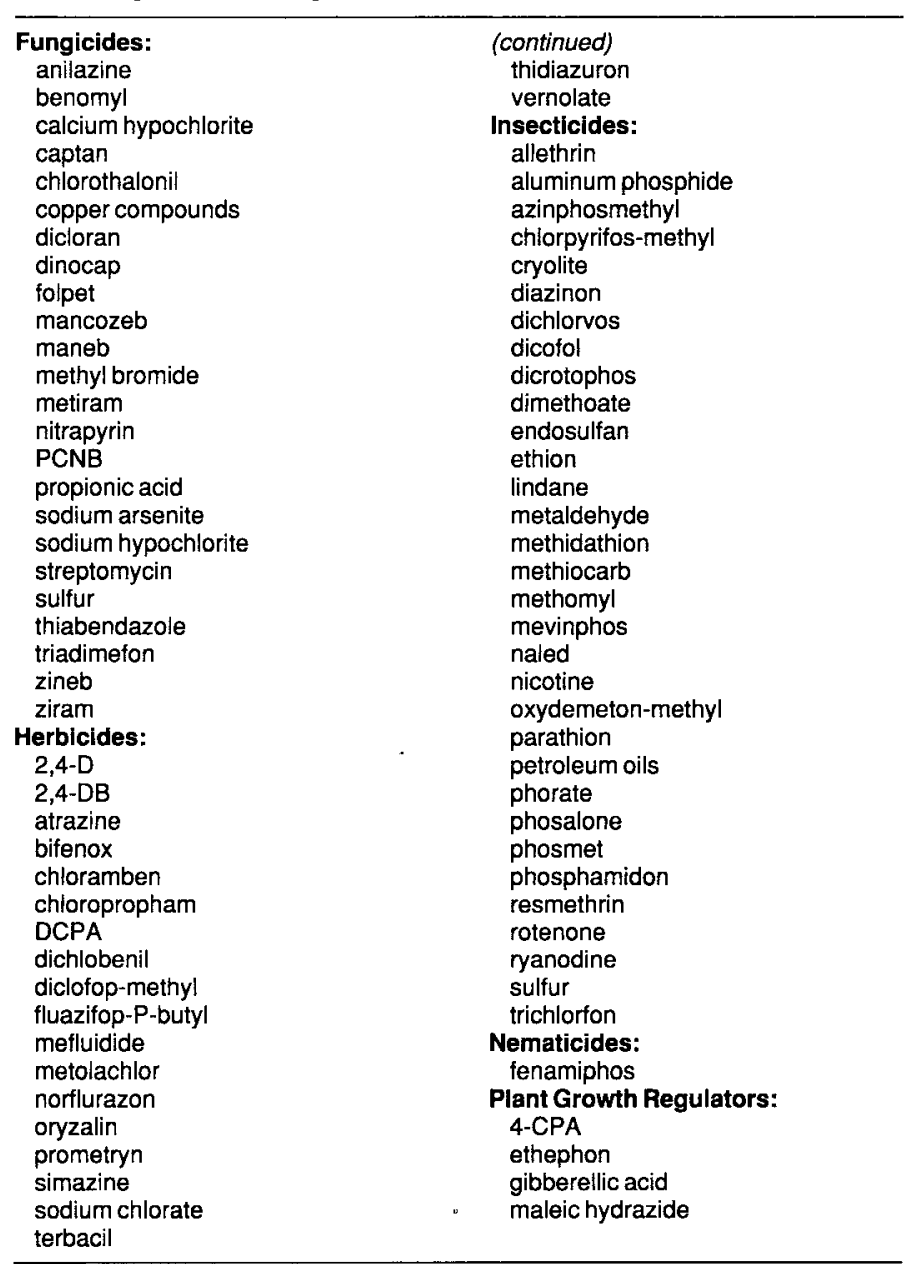

*SOURCE: IR-4 reregistration database, 1990.
The active ingredients formulated into hundreds of pesticide products may be canceled if EPA 1990 is adopted by California's voters. Additional withdrawals are possible over time as the laws are interpreted and as pesticide registrants decide to withdraw registrations. Combined, these three laws would result in major modifications of current pesticide use.

Tables 1,2, and 3 respectively present our estimate of the chemicals affected by Proposition 65, FIFRA 1988, and EPA 1990, as well as the criteria for inclusion on those lists. The tables summarize potential use cancellations that may result from each of the three laws. Twenty registered active ingredients are covered by Proposition 65 . FIFRA 1988 affects 80 registered pesticide ingredients and EPA 1990 could force cancellation of at least 40 active ingredients. No major pesticide classification is exempt; fungicides, herbicides, insecticides, and nematicides all are affected. The total number of registrations, the total number of formulations, and the total number of uses for the active ingredients that may be canceled by FIFRA 1988 and EPA 1990 (tables 2 and 3) have not been determined at this time.

\section{Two existing laws}

Proposition 65, theSafe Drinking Water and Toxic Enforcement Act, does not cancel pesticide registrations. The law provides information to consumers at the marketplace and restricts the discharge of certain chemicals into the waterways. The law establishes a scien-

TABLE 3. Potential pesticide registration actions under EPA 1990

IMPACT: The Environmental Protection Act of 1990 is an initiative that, if approved by California's voters, would result in the cancellation of all food crop uses of the listed pesticides over a period of approximately 5 to 13 years.

CRITERIA FOR INCLUSION ON THIS LIST: Chemical metabolite or contaminant designated as $\mathrm{B}$ or $\mathrm{C}$ carcinogen by EPA or as a carcinogen or terratogen under Proposition 65.

LIST: 40 registered active ingredients

\begin{tabular}{|c|c|}
\hline $\begin{array}{l}\text { Fungicides: } \\
\text { benomyl* } \\
\text { captan } \\
\text { chlorothalonil } \\
\text { folpet } \\
\text { formaidehyde } \\
\text { fosetyl-al" } \\
\text { mancozeb } \\
\text { maneb } \\
\text { metiram } \\
\text { sodium arsenite } \\
\text { thiophanate methyl } \\
\text { zineb } \\
\text { Herbicides: } \\
\text { acifluorfen } \\
\text { alachlor } \\
\text { atrazine } \\
\text { bromoxynil" }^{*} \\
\text { diclofop methyl* } \\
\text { linuron* } \\
\text { metolachlor } \\
\text { oryzalin** } \\
\text { oxadiazon }\end{array}$ & $\begin{array}{l}\text { (continued) } \\
\text { oxyfluorfen* } \\
\text { simazine* } \\
\text { trifluralin* } \\
\text { Insecticides: } \\
\text { acephate* }^{*} \\
\text { amitraz* }^{*} \\
\text { cypermethrin* } \\
\text { dichlorvos } \\
\text { dicofol } \\
\text { lindane } \\
\text { methidathion* } \\
\text { paradichlorobenzene } \\
\text { parathion* } \\
\text { permethrin* } \\
\text { phosmet* } \\
\text { phosphamidon* } \\
\text { Nematicides: } \\
\text { 1,3-dichloropropene } \\
\text { Others: } \\
\text { ethylene oxide } \\
\text { propylene oxide } \\
\text { warfarin }\end{array}$ \\
\hline
\end{tabular}

"C-list compound, will retain registration only if evaluated as being non-carcinogenic within 10 to 13 years.

TABLE 4. Inert ingredients causing potential pesticide product cancellations as a result of the Environmental Protection Act of 1990

\begin{tabular}{ll}
\hline \hline acetaldehyde & (continued) \\
benzene & methylene chloride \\
ethyl alcohol & methylene oxide \\
ethylene oxide & mineral oils \\
formaldehyde & silica (respirable, crystalline) \\
heavy metals & soots \\
lead & tars \\
\hline
\end{tabular}

Pesticide products containing the above-listed inert ingredients will be canceled under EPA 1990. To retain registration, registrants will have to reformulate using other inert ing redients or will have to remove the contaminants in the intentionally added inert ingredients. SOURCE: CDFA 1990. 
tific advisory panel and requires that the State of California develop a list of chemicals known to cause cancer or reproductive toxicity.

Under the labeling provisions of the law, any person who may be exposed to a listed chemical at a significant level must be warned of that possibility when any product contains amounts of a chemical on the list that represent a significant risk. Generally, the warnings are signs or labels displayed where the product is sold. Pesticide-treated commodities were exempted from the warning label requirement, but a recent court decision requires such labels on agricultural commodities. That decision is under appeal. The water quality provisions of Proposition 65, if implemented, would impose heavy fines on those responsible for the discharge of a listed chemical into any waterway. Thus, the law established by Proposition 65 does not itself remove pesticides from use. However, growers may be unwilling to use those materials or the manufacturers may withdraw California registrations if they will be subject to commodity labeling requirements, or if they will risk substantial fines as a result of illegal discharges into any waterway.

TABLE 5. Pesticide use on several major California crops for 1988 (those in bold may be subject to cancellation as a result of FIFRA 1988 or EPA 1990)

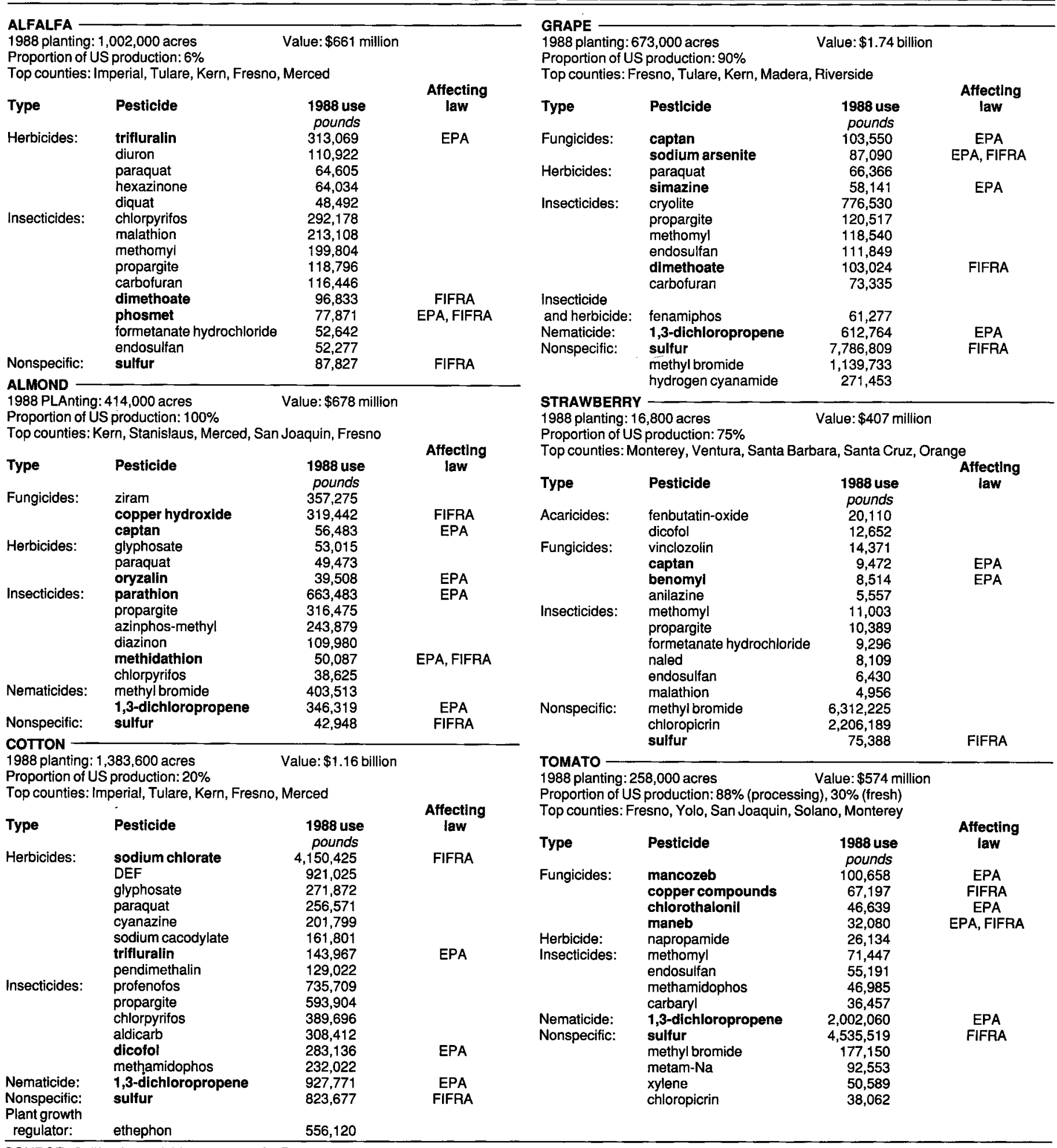

SOURCE: California pesticide use report, CDFA 1988. 
The Federal Insecticide, Fungicide, and Rodenticide Act was amended in 1988 (FIFRA 1988) to require accelerated reregistration of pesticides for which the U.S. Environmental Protection Agency did not have complete registration data. Federal reregistration is scheduled for completion in 1997. Companies will lose registrations before 1997 if they do not agree to provide data or do not pay reregistration fees. Under FIFRA 1988, cancellations will occur if EPA determines the pesticide should not be reregistered for use. In addition, registrants may voluntarily withdraw pesticide registrations when they estimate that their costs for continued registration exceed potential sales revenue, or when liability outweighs the potential profits.

\section{EPA 1990}

If approved by California voters, the Environmental Protection Act of 1990 (EPA 1990) could ultimately be the most far-reaching of these three laws. This measure focuses on the carcinogenic potential of registered pesticides. It would eventually force cancellation of a significant number of pesticides included on the U.S. Environmental Protection Agency's lists of chemicals evaluated for carcinogenic potential. The agency's " $A$ " list is limited to those chemicals known to be human carcinogens. Chemicals on the " $B$ " list are those classified by the agency as probable human carcinogens. Under EPA 1990 , registrations of the chemicals on the " $A$ " and " $B$ " lists would be canceled and their tolerances revoked by January 1, 1996. If it were shown at that time that no effective alternative were available, the Director of Health Services could authorize an additional 3 years' use, requiring a $10 \%$ reduction in use each year, before cancellation.

For chemicals that are on the agency' ${ }^{\text {" }} \mathrm{C}$ " list because they are considered possible human carcinogens, the registrants would have to petition for a determination of non-carcinogenicity if they wished to retain registration. Petitions would be due by November 7,1994. If the chemical were determined to be a probable human carcinogen, its registration would be canceled and its tolerance revoked by the year 2001. The optional 3-year extension could also be authorized. If the chemical were determined not to be a probable human carcinogen, its registration would remain in effect.

EPA 1990 also has a provision stating that all other pesticide tolerances must be evaluated by the State Department of Health Services by January 1, 1997, and revised or revoked by January 1 , 1998.

EPA 1990 incorporates the pesticides covered by the Proposition 65 list, and would eventually result in their cancellation. It would also prohibit the importation into California of commodities carrying residues of pesticides on that list or the EPA 1990 list. Most of these cancellations would become effective on January 1, 1996.

Most pesticide formulations include various inert ingredients in order to make effective products. EPA 1990 defines inert ingredients to include any ingredients that are not active, and contaminants, metabolites, or degradation products in the formulated pesticide. Specific information on most inert ingredients is considered a trade secret by manufacturers, and is not publicly available. Some of these inert ingredients are included on the Proposition 65 list; 13 inert ingredients meet the same criteria applied to active ingredients and would be added to the EPA 1990 list (table 4). Other inert ingredients not included in table 4 may eventually be shown to present a risk as defined by EPA 1990, and would therefore be subject to a data call-in to support their continued registration. Registrants may be able to find substitutes for intentionally added inert ingredients prohibited under these laws. If the inert ingredient cannot be removed and if registrants cannot provide the required toxicity data, formulated pesticide products will be canceled by the State of California within two years of the data call-in.

EPA 1990 includes a clause that may eventually prove very significant. The initiative would set the maximum allowable risk of carcinogenicity to an exposed population at one case in one million. This risk would be determined using the most conservative risk assessment model that is accepted as scientifically valid. The initiative states that this "...shall also apply to other adverse health effects of any pesticide as to which there is no generally accepted scientifically valid threshold below which exposure is safe...." Depending on future interpretation, this portion of the initiative could impact any pesticide that shows any measurable neurological, behavioral, or reproductive activity in test animals. It could also affect pesticides shown to be mutagenic in higher organisms. We cannot predict with certainty, however, how this portion of the initiative would be interpreted. Since EPA 1990 includes no provision for review by a recognized scientific advisory organization, the process for establishment of standards and the technical determination of scientifically valid thresholds remains unclear.

\section{Lost technology: industry shifts}

These three laws may cause progressive losses of pest management chemicals for the farming industry. Table 5 lists six of California's top-value crops for 1988 and shows their dollar value, acreage, and major pesticide uses, and potential effects of FIFRA 1988 and EPA 1990. Implementing acceptable alternative pest management strategies to replace the targeted pesticides over the next five years would be expensive, and require increased research and extension programs and, perhaps, major adjustments in agricultural production and management systems. The companion article by Zalom and Strand identifies alternatives that UC pest management experts believe might replace the targeted pesticides presented here in tables 2 and 3. Included among these are many technologies that are only partially developed and have not yet proven to be efficacious and economical.

No general statement can be made as to the availability of alternatives. Alternatives can only be approached specifically, crop-bycrop, pest-by-pest. For example, the data presented by Zalom and Strand (their table 1) indicate that chlorothalonil, one fungicide targeted under both FIFRA 1988 and EPA 1990, has two available alternatives (other fungicides) for use on soft fruits, but none for cole crops. In addition, on onions, potatoes, and tomatoes chlorothalonil is important, but we do not know the status of possible alternatives. In short, most pesticide alternatives are very specific in their action, so they must be developed individually for each crop-pest situation.

Whether required immediately as some compounds are withdrawn by their registrants under FIFRA, or more gradually as chemicals are phased out over 5 to 13 years under EPA 1990, the implementation of economically viable alternatives to the pesticides to be removed from use will be expensive and require an accelerated research and development program. However, California's agriculture has proven to be a resilient industry, and with time efficacious and economical alternatives may be developed for the targeted pesticides. The review presented in this paper and the two that follow will help the University develop its research and extension agenda to develop new pest management guidelines to replace those involving the targeted pesticides. Supplying scientifically sound, efficacious, and economical alternatives will be a major challenge.

\section{Selected references}

Federal Register, "Regulation of pesticides in food: addressing the Delany paradox policy statement; Notice," October 19,1988.

Internal California Department of Food and Agriculture memorandum, "Analysis of the Environmental Protection Act of 1990," Jennifer Boursier, January 10, 1990.

IR-4 reregistration database, January 1990.

California pesticide use report, California Department of Food and Agriculture, 1988.

Environmental Protection Act of 1990, an Initiative Measure to be Submitted Directly to the Voters.

Federal Insecticide Fungicide and Rodenticide Act as amended 1988. 
Linda J. Fisher, U.S. Environmental Protection Agency, letter to Henry A. Waxman, U.S. Congress. May 1990, Attachment 1. Food Use Pesticides which have been Evaluated for Carcinogenicity.

The authors wish to thank Jennifer Boursier, Legislative Coordinator for the California Department of Food and Agriculture, and Jerry J. Baron,
Associate Coordinator for IR-4 National Headquarters, Rutgers University, for their assistance in this project.

Michael W. Stimmann is Statewide Pesticide Coordinator, UC DANR, based at UC Davis; and Mary P. Ferguson is Special Assistant for Microbial Pesticide Registration for IR-4, a nationwide program to support the registration of pesticides on minor crops, and is also based at UC Davis.

\title{
Alternatives to targeted pesticides: the DANR database
}

\author{
Frank G. Zalom - Joyce F. Strand
}

Late in 1989, the Division of Agriculture and Natural Resources (DANR) initiated an inventory of alternatives to pesticides and specific crop uses that would be lost under FIFRA 1988 and EPA 1990. A committee of University of California pest management specialists and agricultural economists developed a survey asking respondents to provide information on the number and frequency of applications, application method, and target pest for each crop and targeted pesticide for which they felt they had sufficient expertise.

The questionnaire also asked for alternative pesticides, their method and frequency of application, expected yield and quality compared to those with the targeted pesticide, and deficiencies or problems with the proposed alternative. Similarly, it asked for nonchemical alternatives or alternative systems, the cost of the alternative or the data required to determine that cost, the yield and quality compared to those with the targeted pesticide, and deficiencies or constraints to the use of the alternative. The questionnaire and a draft of Stimmann and Ferguson's article Potential pesticide use cancellations in California went to 140 Cooperative Extension advisors and specialists, Agricultural Experiment Station faculty, and USDA-Agricultural Research Service researchers with experience in pest management on California agricultural crops. Seventy people responded with 760 completed questionnaires. A database was assembled that classified and summarized the responses by crop, target pesticide, and target pest.

In the next step, a specialist from each of the pest management disciplines - plant pathology, nematology, entomology, and weed science - was asked to assemble a workgroup of other research and extension experts in his or her discipline to review the database summaries and to reach a consensus on each survey item, including establishment of the present availability of each alternative (ignoring cost), correction of any inaccuracies, and filling in of data gaps. The four workgroups comprised more than 40 individuals. The results were added to the database.

Pest management methods were categorized as biological, cultural, or chemical, with further subdivisions as follows:

\section{Biological alternatives}

- Biological control by multicellular organisms - including release of exotic parasites and predators, conservation and augmentation of natural enemies, genetic improvement of natural enemies, and allelopathy

- Biological control by microbial agents - application of beneficial or antagonistic living microorganisms or toxins synthesized by microbial agents

- Management practices - including natural mulches, living mulches, trap crops, and cover crops to enhance natural enemies or to control pest species

\section{Organically acceptable chemical alternatives}

- Oils and soaps - some horticultural oils and various fatty acids

- Botanicals - toxins derived from plants, such as pyrethrum and ryania

- Semiochemicals - pheromones, allomones, and kairomones, including sex attractants, feeding attractants, and repellants produced by insects and affecting the behavior of other insects

- Inorganic or elemental compounds - such as elemental sulfur and some copper formulations

\section{Synthetic organic chemicals}

- Synthetic organic pesticides - including chlorinated hydrocarbons, organophosphates, carbamates, pyrethroids, and insect growth regulators

- Fertilizers - use of commercial fertilizers in control of a pest species

\section{Cultural alternatives}

- Crop rotation - rotation of various lengths and fallow periods

- Physical controls - such as tillage, mowing, chopping, and flaming

- Sanitation - removing noncrop hosts and infested hosts

- Pruning and canopy management - physically manipulating the structure of the host plant

- Irrigation management - controlling water application and drainage

- Strategic choices - choice of field, location, planting and intended harvest dates, vigorous cultivars, plant density, transplanting, etc.

- Regulation - including mandatory host-free periods, hostfree zones, crop termination, seed indexing, and detection

\section{Genetics and plant improvement}

- Host plant resistance - including cultivars and rootstocks

\section{Status of the database}

All the data that have been received have been entered into the database. The data address pesticides targeted by FIFRA 1988 and EPA 1990, including 14 fungicides, 12 herbicides, 26 insecticides, and 1 nematicide. Data for the fungicides are available on 44 crops, for the herbicides on 45 crops, for the insecticides on 60 crops, and for the nematicide on 63 crops. Almost 600 crop and pest situations are addressed. The database includes biological, cultural, or chemical alternatives for each targeted pesticide, crop, and pest identified by the specialists who contributed the information. The current status of a given alternative (i.e., its availability) is also provided. 